\title{
De indígena a maya: Efectos y potencia de la transformación discursiva
}

\author{
Walter Paniagua \\ Instituto de Estudios Interétnicos \\ wa_paniagua@yahoo.com.mx
}

Director/a: Juan Muñoz Justicia

Mi principal interés al escribir sobre Guatemala radica en las prácticas que construyen formas de vida que pueden propiciar un orden social diferente. Por esta razón he planteado la presente investigación que tiene por objeto de estudio, los efectos que produjo el cambio discursivo de indígena a maya y su potenciación a partir de la reapropiación de términos insultantes.

Desde hace algunos años, el término "maya" ha sufrido una metamorfosis dentro de las prácticas lingüísticas de los guatemaltecos y guatemaltecas. La configuración social del país a raíz de varios sucesos como el conflicto armado (1960-1996), la politización de identidades, las transformaciones locales y la introducción de ayuda internacional, entre otros (Esquit, 2003), han propiciado que la categoría "maya" haya sido utilizada como parte importante en un proceso de cambio en las relaciones interétnicas de Guatemala, y que podamos hablar, desde nuestro punto de vista, de un "cambio discursivo".

Si bien históricamente el término maya no ha sido utilizado como referente de identidad étnica o política (Schackt, 2002), nos parece interesante reflexionar sobre los efectos que está produciendo el cambio discursivo de indígena ${ }^{1}$ a maya, como un intento por re-significar los referentes indígenas (Valdez, 2002). Por esta razón, se hará énfasis en el papel que adquiere el término maya, como referente identitario diferente al de indígena.

La utilización de la identidad maya no es generalizada en el país, sin embargo, con las distintas actividades que promueven los nuevos mayas se ha ido creando un imaginario al respecto de esta nueva identidad.

${ }^{1}$ En este proyecto de investigación se tomarán como sinónimos los términos indígena e "indio". Sin embargo es necesario aclarar que estas categorías han tenido un uso y desarrollo diferente en Guatemala. En principio, indígena es la palabra políticamente correcta para referirse a los nuevos mayas y su origen puede remitirse, aproximadamente, a la reforma liberal guatemalteca en 1871 . Documentos de esa época hacen referencia a los nativos del país como indígenas, no obstante para la oligarquía y ciertos sectores no indígenas, el término siguió manteniendo los mismos referentes de la colonia con respecto al "indio" (Taracena, 2002). 


\section{El lenguaje y la construcción de identidades}

Uno de los temas a los que se recurre insistentemente durante todo el trabajo, es la influencia que tiene el lenguaje en la construcción de identidades, en particular, cuando han sido identidades creadas para mantener cierto tipo de prácticas de dominación. Este fue el caso del "indio" guatemalteco, un sujeto creado a partir de la invasión de los españoles y construido desde un imaginario que visualizaba a individuos abyectos, deshumanizados e indignos, como excusa para sostener una supuesta superioridad en las relaciones cotidianas de la colonia. Como cualquier idea que fuera potencialmente desestabilizante del bienestar alcanzado por los españoles en tierras americanas, o que se saliera de los criterios normativos de la época, se le debía adjudicar a ese sujeto un nombre que le representara e identificara como colectivo y sujeto diferente.

Los europeos y los criollos emplearon el lenguaje como herramienta para crear una realidad que les convenía. La construcción de los "indios" se realizó, en gran medida, a través de la manera en que los no indígenas hablaron, escribieron, discutieron, etc, sobre ellos durante la colonia. Se les instauró -a los indígenas- como ese conglomerado de "otros" que eran indispensables para el desarrollo y explotación económica del territorio, pero al mismo tiempo no deseable dada la posición identitaria a la que fueron sujetos (Esquit, 2002). Se necesitaba que existiera un sujeto sometido, con una serie de características, convenidas por los españoles, para mantener el estatus y la forma de vida proyectada para la colonia.

\section{Posibilidades de mayanidad:}

Este tipo de pensamiento con respecto a los indígenas siguió constante hasta más o menos hasta ya entrado el siglo XX, específicamente con un suceso que convulsionó al país y que fue una parte importante para las posibilidades de mayanidad: el conflicto armado interno.

La conciencia de una identidad negativa (en tanto que conocimiento de quiénes somos, cuáles son nuestras raíces y porqué estamos así) por parte de los indígenas fue dilucidada, posiblemente, por la "lucha de clases" promovida por la insurgencia guatemalteca. El surgimiento de conciencia "del ser indígena" se debió en gran parte, a las condiciones de precariedad económica que vivían este colectivo en el país.

El recrudecimiento de la guerra interna hizo que mucho del trabajo que hacían las organizaciones indígenas perdiera fuerza, no obstante en 1992 hubo un repunte de estas organizaciones con la conmemoración de los 500 años de la llegada de los españoles. En Guatemala, la premisa de los activistas indígenas era que la identidad étnica también es un elemento importante en la discusión de los derechos. Las ideas sobre el indigenismo fue una de las grandes plataformas que las organizaciones "populares" y "culturalistas" utilizaron en sus demandas ante el Estado, por lo que se empezó a profundizar en referentes más o menos cercanos (la extinguida cultura Maya) para crear un uso político de la identidad/self ${ }^{2}$.

\footnotetext{
${ }^{2}$ Dentro de los referentes teóricos que se usan en la investigación se hace la distinción entre el uso de la palabra identidad y self. La diferencia entre estos término radica en que el concepto de identidad está relacionado con la producción psicológica y social más convencional de la identificación, la cual refiere a cuestiones sustanciales; a diferencia del self que está vinculado con orientaciones más
} 


\section{Crítica a la categoría "indio" y otros efectos de la transformación}

Con la aparición del self maya se posibilitó la materialización de actividades conjuntamente elaboradas para todos los miembros del grupo, que a partir de los incipientes procesos de "mayanización", forman la nueva subjetividad maya. Es necesario aclarar que este proceso de subjetivación está habilitado por la militancia política de los integrantes del movimiento Maya, y aunque en gran parte de las comunidades no se reconocen como mayas, creo que no se tendría que buscar la objetividad de los hechos históricos para fundamentar un discurso de lo maya, o la producción de sujetos mayas, sino que se debería de profundizar en los fundamentos pragmáticos que logran reunir a varias comunidades dispersas en un "pueblo" unificado por una historia y una organización sociocultural-digámosle- común.

A pesar de que la "mayanización" se desarrolla lentamente, al menos un par de cosas son evidentes en este proceso de reafirmación, a decir, la lucha de los derechos de igualdad frente al grupo no indígena y el cuestionamiento de etiquetas peyorativas a partir de la introducción del término maya.

Muchas personas creerán que con cambiar de nombre al conglomerado indígena no se hace mucho, pero, al momento en que el lenguaje se vuelve ofensivo o hiriente se convierte en formas habituales de interrelación. Las consecuencias que se derivan del habla son el principal motivo para que surja la necesidad de un cambio o re-significación de los términos.

Cuando un término ofensivo hiere (para este caso la palabra "indio"), lleva a cabo el daño a través de la acumulación y disimulación de su fuerza. Al momento en que el hablante cita la palabra en cuestión, establece una comunidad lingüística con la historia de hablantes que usan o usaron ese enunciado de forma peyorativa (Butler, 1997). Las frases que se emplean en Guatemala para denigrar a un individuo entre los no indígenas -aunque no todos-, consciente o inconscientemente, pasan a menudo por las expresiones como "no seas indio", "indio relamido", "mija" entre otras, que denigran a los indígenas.

La crítica a la categoría "indio" se posibilita, en primera instancia, con la formulación discursiva de los nuevos referentes mayas, es decir; al hablar de procesos de mayanización entiendo las producciones de subjetividad del colectivo como un haz de contingencias que, aunque refieren a un imaginario histórico, no lo hacen de manera fundamental. Por ejemplo en Nebaj, municipio del Quiché, la mayor parte de personas con las que he intercambiado algunas charlas se reconocen como mayas, pero son mayas-ixiles que proponen que sus raíces históricas pueden estar mezcladas con el pasado prehispánico, pero no necesariamente se fundamenta ahí. Es en el presente con la politización de su self $\mathrm{y}$, principalmente con las posibilidades que surgen de la concienciación Ixil, que las personas van moldeando su propia subjetividad.

Si las transformaciones de ciertas prácticas lingüísticas habilitan procesos de subjetivación, se puede pensar que esta subjetividad se hace evidente en esas prácticas que se dan día a día en los distintos colectivos mayas. Ejemplos que se pueden mencionar son la revalorización de la espiritualidad maya,

novedosas en la psicología social en donde su producción es relacional y contingente (Iñiguez, 2001; Pujal, 2003) 
la medicina tradicional y el Derecho Consuetudinario (derecho indígena). Estos tres referentes son parte fundamental en la propia percepción y cultura de los mayas, sin embargo, por cuestiones de espacio sólo los menciono como efectos de la transformación discursiva que ayudan a fortalecer los distintos selves mayas.

\section{Identidades/selves subversivas frente a modelos normativos}

Explicada la importancia de la cohesión que pueden producir las acciones conjuntas del colectivo maya, terminaré el ensayo analizando cómo una re-significación de términos insultantes como "indio" o indígena funciona como potencia y actualización para transformaciones discursivas al producir nuevas formas de legitimación al hablar. Por supuesto, esto siempre y cuando el cambio sea producto de procesos éticos-afectivos y no impuesto a partir de exigencias judiciales o fuera de las competencias comunitarias. Hasta ahora he enfatizado en las cuestiones positivas de la transformación discursiva de indígena a maya y los efectos que ha tenido, sin embargo, intentaremos hacer una aproximación a la teoría de la performatividad de Judith Butler.

La autora recurre a la crítica derridiana del performativo de J. L. Austin en Cómo hacer cosas con palabras, de donde surge su teoría de la performatividad. Butler propone que la performatividad no es un acto único, sino una repetición y un ritual que logra su efecto mediante su naturalización dependiendo del contexto (Butler 1990) Por lo que habría que entender la performatividad como

"la práctica reiterativa y referencial mediante la cual el discurso produce los efectos que nombra" (Butler 1993: 18)

Hay que dejar claro que cuando se dice que la performatividad produce los efectos que nombra, no quiere decir que el sujeto otorgue vida a aquello que enuncia, más bien, se habla de cómo el poder reiterativo del discurso produce los fenómenos que regula e impone. Como he expuesto en los capítulos anteriores, los discursos en torno al "indio" o indígena en Guatemala además de producir los sujetos en cuestión, produjeron efectos en las relaciones étnicas al nombrarlos.

Gil (2002) menciona que el acto preformativo produce efectos, construye la realidad como efecto del acto ejecutado. La performatividad supone la idea de que el sujeto construye la realidad de su propia identidad mediante los actos lingüísticos que ejecuta, y de esta manera cuestiona ideas esencialistas en las identidades, sean estas de tipo sexual o no. Pudiera ser que para el análisis que efectúa Butler de la identidad sexual en travestidos sea más explícito por la performance (actuación) que se hace, pero para el caso étnico que proponemos también existen actividades que pueden ser tomadas como actuaciones.

Por ejemplo, puede ser justificado que la idea de "mayanidad" como ha sido desarrollada hasta ahora, se estructure con herramientas heredadas del legado moderno de la reforma Liberal guatemalteca desde 1871, y al igual que pasa con la identidad del ladino, se puede correr el riesgo de visualizar ambas identidades como esencialistas. Algunas personas de los círculos intelectuales guatemaltecos y del movimiento maya, intentan apelar a las características ontológicas de la "mayanidad" como reacción a la serie de atrocidades cometidas en contra de los pueblos indígenas durante la historia; es legítimo hacerlo, no obstante a parecer simplistas, existen matices dentro de las diferentes agrupaciones panmayas mucho más interesantes que no necesariamente poseen vetas rígidas 
respecto a sus identidades/selves como definidora y limitante. Si el esfuerzo del colectivo maya toma el rumbo de identificar a un enemigo étnico o político diferenciado fundamentalistamente, las acciones se prestarían para formar un discurso invertido que imitaría la estrategia de asimilación y exclusión de la reforma liberal guatemalteca; antes que ofrecer una serie de posiciones diferentes de militancia y convivencia entre mayas y el resto de comunidades.

Afirmar que las identidades se actúan (performances) y que cada vez que se da la repetición de la actuación no quiere decir que se produzcan el efecto de una esencia. Cualquier identidad está constantemente amenazada por el exterior que ella misma constituye y además, es abierta a procesos de rearticulación y redefinición de sus límites. Las identidades/selves así como lo sujetos no son esencias sino formas que mutan (Foucault 1984) y nunca se mantienen idénticas a sí mismas: se juegan, se truecan, se establecen respecto a nosotros mismos como oportunidades de relaciones diferentes.

Considerar la constitución subjetiva de la identidad maya en términos de performatividad implica rechazar una aproximación descriptiva de la misma. Con esto me opongo a la representación de una idea exacta de lo maya, al menos de los nuevos mayas guatemaltecos. Lo que acaba uniendo a un nombre con un conjunto de sujetos no son una serie de rasgos esenciales que comparten todos ellos como conglomerado, sino el acto mismo de su nominación o identificación con ese nombre de forma estratégica o intencional (Butler 1993, 1997, Gil 2002, Córdoba 2003).

Puede ser que los procesos de mayanización que se proponen desde diversas esferas académicas, culturales y políticas, funcionen para un cambio en las relaciones interétnicas guatemaltecas; sin

Volvamos al léxico ofensivo que dejamos hace algunos momentos y que, precisamente, es en la interculturalidad donde potenciaría sus efectos. La propuesta que hacemos aquí es una aproximación a las ideas de Butler de la reapropiación de los términos insultantes que aparece en su libro Exitable Speech $(1997)^{3}$ como estrategia para revertir las injurias en identidades excluidas.

De la misma forma que el lenguaje nos sujeta, también nos otorga posibilidades de agencia como acción de abrir nuevos contextos, esto es, hablar de nuevas maneras o legitimar nuevas formas. La noción de agencia se caracteriza por ser una práctica de rearticulación o de re-significación, que es inmanente al poder y no a una mera relación de oposición externa. La agencia no es un atributo de los sujetos, se ubica en el carácter performativo del significante político (Butler 1990) por lo que la

Mencionaba que la exposición pública de la ofensa verbal es también una repetición, pero no sólo se trata de eso, puesto que lo que se expone con el enunciado no siempre es exactamente lo que se quiere decir y es en esa afortunada inconmensurabilidad que otorga el lenguaje donde reside la oportunidad lingüística de cambio.

"Si las frases cargan con significados equívocos, entonces su poder es, en principio, menos unilateral y seguro de lo que parece. De hecho, la equivocidad del enunciado significa que puede que no siempre signifique de la misma manera, que su significado puede ser invertido o desviado de alguna manera significativa y, más importante todavía, significa que las palabras mismas que tratan de herir pueden

\footnotetext{
3 Traducción al castellano como Identidad, lenguaje y poder. Editorial Síntesis Madrid 2004
} 
igualmente errar su blanco y producir un efecto contrario al deseado" (Butler 1997: 148)

La separación entre el significante y el enunciado habilita esta propuesta. Puesto que nadie ha superado una injuria sin repetirla, ésta repetición sería la continuación de aquello que marca distancia, que hiere pero que a su vez nos dota de posibilidades constitutivas para actuar de otra manera (Butler 1997). No existe la posibilidad de no repetir las injurias, en el sentido que seguirá siendo habitual el uso de los términos como "indio" o de forma sofisticada como maya; la única cuestión que nos preguntamos es ¿la persona que sufrirá el agravio será alguien con el estatus de la Dr. Menchú? o ¿en qué lugar se dará esa repetición, los juzgados, la calle, el mercado, la escuela, el bus? y en particular ¿con qué dolor o con qué promesa? Si expresiones peyorativas como "indio" son re-significadas o re-contextualizadas adhiriéndose como connotación de orgullo colectivo es mucho más probable que las ideas y prácticas sean tomadas como situaciones éticas y afectivas con nosotros mismos y los demás antes que políticas impuestas por agentes que muchas veces sentimos ajenos a nuestra colectividad.

Lo que se pone en juego con la re-apropiación y uso de las palabras que han funcionado como insultos es la subversión del significado por medio de una descontextualización y re-contextualización de esos nombres y del carácter performativo de producción de su identidad (Córdoba 2003). Quizás en el momento en que la identidad/self indígena sea usada de manera subversiva, como actitud positiva de orgullo, ante los modelos normativos o hegemónicos, la re-apropiación potenciaría nuevos cambios en los formas de subjetivación dando paso a cambios en las prácticas interétnicas de los guatemaltecos y guatemaltecas.

Es difícil y duro el trabajo que se tendría que elaborar al respecto de la re-significación en Guatemala, y en su intento se podrían herir muchas susceptibilidades dejando marcas profundas en la gente, pero precisamente, la adscripción consiste en la re-apropiación por el agente de su propia reflexión al "estar en" el mundo; significa decidirse a resolver la discusión haciendo propias las opciones que habilita el insulto. Quedarse en lo políticamente correcto hace que las categorías se conviertan en simples eufemismos o neologismos académicos. No se cambia el significante que sustenta el enunciado o, en otras palabras, la idea podría seguir siendo la misma con el nombre que se le atribuya. Ejemplos muy claros de esto son hablar de "países en vías de desarrollo" en vez de países subdesarrollados, o "trabajadoras del sexo" para citar a las putas. La idea viene siendo la misma y los prejuicios también. Por eso al igual que Butler nos hacemos el cuestionamiento de con qué dolor o con qué esperanza funcionaría la re-significación para la comunidad maya.

\section{Referencias}

Austin, John. (1962) “Cómo hacer cosas con palabras: palabras y acciones” Paidós Barcelona 1998

Barth Frederich. (1979) "Los grupos étnicos y sus fronteras" Fondo de cultura económica México 1990.

Butler Judith (1990) "Gender trouble. Feminism and the subversion on identity" London: Routledge

Butler Judith (1993) "Cuerpos que importan. Sobre los límites materiales y discursivos del sexo" Paidós Argentina 2002

Butler Judith (1997) “Identidad, lenguaje y poder”. Editorial Síntesis, España 2004. 
Córdoba, David (2003) "Identidad sexual y performatividad" Atenea Digital 4, 87-96. extraido el 4 de octubre de 2005 http://antalya.uab.es/athenea/num4/cordoba.pdf

Esquit, Edgar. (2002) "Otros poderes, nuevos desafíos. Relaciones Interétnicas en Tecpán y su entorno departamental 1971-1935" IDEI-USAC Guatemala

Esquit, Edgar (2003) “Caminando hacia la utopía. La lucha política de las organizaciones mayas y el Estado en Guatemala” Colección Reflexiones 4 Instituto de Estudios Interétnicos USAC, Guatemala.

Foucault, Michel (1984) "La hermenéutica del sujeto" En Foucault M. "Estética, ética y Hermenéutica" Paidos Barcelona, Tomo III. 1999.

Gil, Eva (2002) "Por qué le llaman género cuando quieren decir sexo?: una aproximación a la teoría de la performatividad de Judith Butler" Atenea digital, 2. extraído el 4 de octubre de 2005 http://blues.uab.es/athenea/num2/Gil.pdf

Schackt, John. (2002) "Los Mayas: Origen del término y creación del pueblo". En De Indígena a Maya: Identidades indígenas en Guatemala y Chiapas. Schackt J. (Editor) Instituto de Estudios Interétnicos USAC. Guatemala 2002

Valdez, Angel (2002) "Las identidades étnicas y el Estado-Nación" En De Indígena a Maya: Identidades indígenas en Guatemala y Chiapas. Schackt J. (Editor) Instituto de Estudios Interétnicos USAC. Guatemala 